\title{
An agenda-setting model of electoral competition
}

\author{
Josep M. Colomer • Humberto Llavador
}

Received: 2 October 2010 / Accepted: 23 March 2011 / Published online: 6 April 2011 (C) The Author(s) 2011. This article is published with open access at SpringerLink.com

\begin{abstract}
This paper presents a model of electoral competition focusing on the formation of the public agenda. An incumbent government and a challenger party in opposition compete in elections by choosing the issues that will key out their campaigns. Giving salience to an issue implies proposing an innovative policy proposal, alternative to the status-quo. Parties trade off the issues with high salience in voters' concerns and those with broad agreement on some alternative policy proposal. Each party expects a higher probability of victory if the issue it chooses becomes salient in the voters' decision. But remarkably, the issues which are considered the most important ones by a majority of voters may not be given salience during the electoral campaign. An incumbent government may survive in spite of its bad policy performance if there is no sufficiently broad agreement on a policy alternative. We illustrate the analytical potential of the model with the case of the United States presidential election in 2004.
\end{abstract}

Keywords Agenda - Elections · Political competition · Issues - Salience - Agreement

\section{JEL Classification D72}

J. M. Colomer acknowledges the support of the Spanish Ministry of Science and Innovation (SEJ2006-10974).

H. Llavador acknowledges the support of the Barcelona GSE, of the Government of Catalonia, and of the Spanish Ministry of Education and Innovation (SEJ2006-09993/ECO, SEJ2006-10974 and ECO2009-08820).

J. M. Colomer

Institute for Economic Analysis, Higher Council for Scientific Research (IAE-CSIC), Barcelona, Spain

H. Llavador $(\varangle)$

Departament d'Economia i Empresa, Universitat Pompeu Fabra and Barcelona GSE,

R. Trias Fargas 25-27, 08005 Barcelona, Spain

e-mail: humberto.llavador@upf.edu 


\section{Introduction}

On the occasion of the United States presidential election in 2004, former president Bill Clinton, who was not running as candidate, stated: "Generally, the presidential elections in the United States turn always around three questions. First: how one would feel at having that person as president?... As second element there is the candidate's position on certain issues. The third factor is the following: What is this election about? Is it about the United States having a multilateral attitude in foreign policy? Or is it whether taxes should be lowered for the rich or more should be done for the poor?"

In this paper we focus on the third factor: what elections are about. Just to mention an illustration of the relevance of the selection of issues during the electoral campaign, let us also quote somebody involved in the November 4th, 2008 U.S. presidential election. This was published at the beginning of September, just after the two party conventions, when the survey polls showed a close tie between the two main candidates: "'If in October we're talking about Russia and national defense and who can manage America in a difficult world, John McCain will be president', predict[ed] Thomas Rath, the leading Republican strategist in the swing state of New Hampshire. 'If we're talking largely about domestic issues and health care, Barack Obama probably will be president'. Events can affect that conversation. If Russia invades another country on Oct. 20 or Iran detonates a nuclear weapon, advantage McCain; if there's another Bear Stearns meltdown, or a stock market crash, put a few points on the Obama side." (Albert R. Hunt, 'Letter from Washington', New York Times, 8 Sep 2008). Indeed, 1 month later, during the third Presidential Debate in October 15th, Barak Obama pointed out that "Senator McCain's own campaign said publicly last week that, if we keep on talking about the economic crisis, we lose, so we need to change the subject."

This paper discusses the criteria for party choices of issues and the subsequent campaign outcomes. We present a formal model of electoral competition focusing on the formation of the public agenda, in which two political parties or candidates compete to win an election by choosing an issue and a policy position on that issue to which they try to give political salience. Giving salience to an issue implies proposing an innovative policy proposal on the issue as an alternative to the status-quo policy, as well as talking about it, usually with a value or argument, and making it news with some effort investment in order to making it relevant for voters' electoral decisions.

A party will choose a priority issue to campaign for if it is a likely winning issue, that is, if it has a likely winning position and it is likely to become decisive in the election. Whether an issue will become a winning issue depends on two variables: $(i)$ the ex-ante 'pre-campaign or social salience' of the issue in voters' concerns and ( $i$ i) the voters' support or 'agreement' in favor of an alternative policy proposal on the issue.

Thus, parties have to trade off the two variables. If one issue is highly salient in the voters' concerns, but voters are highly divided about which one of the possible policy alternatives to the status-quo is better, choosing to campaign on the issue by holding one of the policy alternatives may be risky. If, on the contrary, there is broad social agreement about the best policy alternative to the status-quo on one issue, but the issue is not a priority for voters' electoral decision, running on that issue can attract little attention. Hence, whether parties compete by raising the same issue and proposing two 
different policy alternatives on it or by choosing different issues does not depend only on voters' priority concerns, but also on each party's likelihood to hold potentially winning policy positions. It is always possible that the issues which are considered the most important ones by a majority of voters be not given political salience by parties during the electoral campaign.

This may be a surprising result, but it may be a reasonable one after all. Important issues in people's concerns can, thus, be solved through electoral competition only when a policy alternative appears as clearly superior to voters' eyes. In the absence of a majority agreement on a best policy alternative, parties can choose not to give salience to the issue, thus maintaining the status-quo policy even if it is unsatisfactory for voters. As a more worrisome consequence, mediocre policies broadly rejected by the electorate, as well as incumbent parties with no good performance in government, may survive.

Foundational works about the importance of agenda-setting in competitive elections include the well-known contributions by Stokes (1963) and Petrocik (1996). They depart in important aspects from the standard 'spatial theory' of electoral competition, in which parties or candidates compete by choosing policy 'positions' on a space which is basically given. There are also a number of collections and analysis of empirical data on issues in electoral platforms (including Riker 1993; Budge 1993; Budge et al. 2001; Petrocik et al. 2003; Klingemann et al. 2006; see the critical review of the literature by Colomer and Puglisi 2005); Baumgartner and Jones (2009) and http://www.policyagendas.org develop and encompassing project on policy agendas including broad empirical material potentially to be analyzed with the framework presented in this article.

However, not a formal model has been elaborated, to our knowledge, which specifies the structural and strategic conditions in which political parties or candidates choose issues in the electoral campaign and shape the relevant policy space. ${ }^{1}$ We discuss these conditions and analyze the type of issues-as defined for their salience in voters' concerns and the acceptation of policy proposals on them-which should be expected to be chosen in equilibrium.

The plan for the rest of the paper is the following. In Sect. 2 we present a spatial model of agenda formation in which parties compete on one issue at a time. For each issue there is some probability of victory for the party holding the most popular policy alternative. We introduce the concepts of issue salience and the degree of agreement on the policy alternative to the status-quo. Section 3 describes issues in the salience-agreement space, and Sect. 4 presents the equilibrium results. Section 5 provides several examples showing that parties can compete on issues with either high salience or broad agreement or both. They do not compete on issues with both low salience among voters and low agreement on the best policy alternative. However, parties may choose not to campaign on those issues with highest salience in voters' concerns, thus postponing solutions to unpopular status-quo policies with considerable social discontent. In Sect. 6, as an illustration, we discuss the choice of campaign

\footnotetext{
1 Amorós and Puy $(2007,2010)$ present a complementary study to our analysis. While the present paper focuses on the selection of issues, in their papers the salient issues are given and they study the allocation of resources to change the saliency in voters' preferences.
} 
issues for the 2004 United States presidential election in the light of the findings in the model. Section 7 concludes.

\section{The model}

Consider an incumbent party in government $(G)$ and a challenger party in opposition $(O)$ that compete to win an election by choosing an issue and a policy position on that issue. There are $N$ potential issues, and for each issue $i=1, \ldots, N$, there exists a status-quo policy $\left(q_{i}\right)$ and two innovative policy proposals located on different sides of $q_{i}$, which can be called $x_{i}$ and $y_{i}$ respectively. If the issue is, for example, taxes, one of the alternatives implies higher taxes, and the other lower taxes, than the status-quo, and similarly for any other issue, so that the two alternatives are on different sides of the status-quo. That is, either $x_{i}<q_{i}<y_{i}$ or $y_{i}<q_{i}<x_{i}$. Denote by $A_{i}=\left\{x_{i}, q_{i}, y_{i}\right\}$ the set alternatives on issue $i .^{2}$

\subsection{Electorate}

Voters have convex preferences over the feasible set of policy alternatives and we assume sincere voting on each issue. For an issue $i$, let $F_{i}\left(a_{i}, a_{i}^{\prime}\right)$ be the fraction of citizens who prefer alternative $a_{i}$ to $a_{i}^{\prime}$, implied by their induced preferences once keeping all other issues constant at the status-quo. Denote by $F_{i}^{x}=F_{i}\left(x_{i}, q_{i}\right)$ and by $F_{i}^{y}=F_{i}\left(y_{i}, q_{i}\right)$ the support for each one of the alternatives against the status-quo. For simplicity, assume that $F_{i}^{x} \neq F_{i}^{y}$ and re-label the alternatives to the status-quo so that $x_{i}$ represents the one with the highest support, $F_{i}^{x}>F_{i}^{y}$.

The assumption that innovative policy proposals are on different sides of the statusquo implies, by the convexity of preferences, that voters who favor alternative $a_{i}$ prefer the status-quo to the other alternative $a_{i}^{\prime}$. Formally, preferences satisfy that, fixing the policy on all other issues, if $x_{i} \succ q_{i}$ then $q_{i} \succ y_{i}$. And similarly, if $y_{i} \succ q_{i}$, then $q_{i} \succ x_{i} \cdot{ }^{3}$ Intuitively, this means, for example, that voters who would like lower taxes would vote against a tax increase by supporting the status-quo.

\subsection{The probability of winning on an issue}

The winning alternative on a particular issue $i$ is the one receiving a majority of votes. Following the literature on electoral uncertainty (Wittman 1983), we assume that parties face uncertainty on the outcome of the election, and no alternative wins with

\footnotetext{
${ }^{2}$ A minimum of three alternatives, with at least one position on each side of the status-quo for each issue, are necessary to obtain a surviving status-quo because of a divided electorate on the best alternative. Nevertheless, the main results from this three-alternative model would continue to hold in a framework where each issue admits a finite number of distinct positions. Therefore, we side with Krasa and Polborn (2010) in arguing that "a setup with very few feasible positions on each issue is actually a quite realistic description of political campaigns" (p. 2).

${ }^{3}$ For the present analysis we only require that the previous conditions on induced preferences hold when all other issues are fixed at the status-quo. Hence, convexity of preferences is a stronger assumption than needed.
} 
probability one. For simplicity, we postulate a generic probability of victory function satisfying a very undemanding condition. ${ }^{4}$

Definition 1 Let $\pi_{i}: A_{i} \times A_{i} \rightarrow(0,1)$ be the probability of victory on issue $i$ function, with $\pi_{i}\left(a_{i}, a_{i}^{\prime}\right)$ representing the probability of victory of $a_{i}$ against $a_{i}^{\prime}$.

Assume that, for each alternative policy, the probability of defeating the statusquo is increasing in the fraction of supporters for that alternative. Formally, denote by $\pi_{i}^{x}=\pi_{i}\left(x_{i}, q_{i}\right)$ and $\pi_{i}^{y}=\pi_{i}\left(y_{i}, q_{i}\right)$ the probabilities that alternatives $x_{i}$ and $y_{i}$ defeat the status-quo on issue $i$. Then, $\pi_{i}^{x}=\varphi_{i}\left(\mathbf{F}_{i}^{x}\right)$ and $\pi_{i}^{y}=\varphi_{i}\left(\mathbf{F}_{i}^{y}\right)$, with $\varphi^{\prime}>0$. In particular, we do not make any assumption on $\pi_{i}\left(x_{i}, y_{i}\right)$, and hence there is no need to specify how voters favoring $q_{i}$ would split if they had to choose between the two alternatives $x_{i}$ and $y_{i}$. For simplicity we fix $\varphi_{i}(1 / 2)=1 / 2 .^{5}$

Because $\mathbf{F}_{i}^{x}>\mathbf{F}_{i}^{y}$, it follows that $\pi_{i}^{x}>\pi_{i}^{y}$, that is $x$ is the advantaged alternative on issue $i$. Without loss of generality, we can sort the issues $i=1, \ldots, N$ according to the probability of victory of the advantaged alternative. We assume for simplicity a strict ordering:

$$
\pi_{1}^{x}>\pi_{2}^{x}>\cdots>\pi_{N-1}^{x}>\pi_{N}^{x}
$$

Suppose that one party has proposed alternative $a_{i} \in A_{i}$ on issue $i$. Given the sequential play analyzed in this paper, we will assume that the other party cannot win by proposing exactly the same alternative on the same issue. Formally, $\pi_{i}\left(a_{i}, a_{i}\right)=0$ for the last party proposing alternative $a_{i}$. That is, given that voters know that one party has announced the policy reform $a_{i}$ (and in a sense that party has acquired the "ownership" of that position), the other party must defend a different position if it wants to compete on that same issue and still hold a positive probability of winning. Combined with the idea that the status-quo belongs to the government, this condition implies that the opposition party cannot defeat an incumbent government on an issue by defending the status-quo, unless the government has proposed first an alternative policy.

\subsection{Issue salience and level of agreement on the policy alternative}

Each issue is characterized by some social or pre-campaign salience, which reflects voters' concerns, and by some agreement on the best policy alternative. Pre-campaign salience and policy agreement are both derived from voters' preferences.

The preferences of voters regarding which issues should be more important in the election can be formed through personal experiences, media emphases, interest groups' promotions or uncontrolled events. But it seems logical that the degree of salience in

\footnotetext{
4 See Chapter 2 in Roemer (2001) for several models of electoral uncertainty which derive a probability of victory function consistent with our setting.

5 None of the qualitative results hinges on this assumption that we make to simplify the exposition.
} 
voters' perception should be related to the degree of social discontent with the statusquo policy on the issue. ${ }^{6}$ In this sense, we measure the salience of issue $i$ in an inverse relation to the support or consensus with the status-quo policy. High-salience implies that a large group of voters $\left(\mathbf{F}_{i}^{x}+\mathbf{F}_{i}^{y}\right)$ disagree on the prevailing status-quo on the issue.

Definition 2 Define the (pre-campaign) salience of issue $i$ as $\sigma_{i}=\mathbf{F}_{i}^{x}+\mathbf{F}_{i}^{y}$.

However, social discontent with the status-quo, and hence high salience, does not necessarily imply a broad agreement on the best policy alternative. It may be, on the contrary, that voters are highly divided on which alternative would be better than the status-quo. We measure the level of agreement as the share of discontented voters who support the most favored alternative to the status quo: $\mathbf{F}_{i}^{x} /\left(\mathbf{F}_{i}^{x}+\mathbf{F}_{i}^{y}\right)$. Normalizing this measure to range from 0 to 1 , we obtain ${ }^{7}$

Definition 3 Define the level of agreement among discontented voters on issue $i$ as

$$
\zeta_{i}=\frac{\mathbf{F}_{i}^{x}-\mathbf{F}_{i}^{y}}{\mathbf{F}_{i}^{x}+\mathbf{F}_{i}^{y}}
$$

Therefore, the maximum value of $\zeta_{i}$ is 1 , when there is total agreement on the best alternative to the status-quo (i.e. $\mathbf{F}_{i}^{y}=0$ ), and the minimum value of $\zeta_{i}$ is 0 , when the discontented electorate is evenly split between the alternatives $x_{i}$ and $y_{i}$ (i.e. $\mathbf{F}_{i}^{x}=\mathbf{F}_{i}^{y}=1 / 2$ ).

\subsection{Post-campaign or political salience}

In order to make an issue decisive in the election, parties try to make it 'salient' in voters' decision by giving it political salience. Parties confer political salience by campaigning on the issue and proposing a policy alternative to the status-quo. Let us call the political salience or post-campaign salience of issue $k$ the probability that $k$ becomes the decisive issue once parties have campaigned on issues $i$ and $j$.

Definition 4 Define the post-campaign salience or political salience of issue $k$ when parties have politicized issues $i$ and $j, s_{i j}(k)$, as the probability that issue $k$ becomes the decisive issue.

We impose the following assumptions on the measure of political salience. First, parties can give political salience to an issue only by proposing a policy alternative to the status-quo. This implies that issues not raised in the electoral campaign do not get

\footnotetext{
6 It might be the case the status-quo was in the past a widely accepted policy with some degree of support. However, it may have become "socially inefficient" or discredited. This can be due to a much higher salience of the issue due to some unforeseen event, technological innovations, voters' new preferences as a consequence of new policies on other issues, or changes in people values. Examples of old status-quo policies that have lost wide support and have become vulnerable to new challenges may include financial regulations, environmental issues, defense spending, communication monopolies, and many others.

7 We construct $\zeta_{i}$ as a linear transformation of $\mathbf{F}_{i}^{x} /\left(\mathbf{F}_{i}^{x}+\mathbf{F}_{i}^{y}\right)$ such that $\zeta_{i}(0)=0$ and $\zeta_{i}(1 / 2)=1$.
} 
salience and hence cannot be decisive. Secondly, if both parties decide to campaign on the same issue, then it becomes the decisive issue since it is the only issue raised during the electoral campaign. Finally, if parties give political salience to two different issues, the probability for each issue to become decisive equals its relative salience.

Assumption 1 Given a pair of issues, $i, j$, chosen by the government and the opposition parties:

1. $s_{i j}(k)=0$ for all $k \notin\{i, j\}$,

2. $s_{i i}(i)=1$ for all $i=1, \ldots, N$,

3. $s_{i j}(i)=\frac{\sigma_{i}}{\sigma_{i}+\sigma_{j}}$ for all $i \neq j$.

It follows that for any pair of different issues, $s_{i j}(i)=1-s_{i j}(j)$. We will write $s_{i j}=s_{i j}(i)$ whenever there is no ambiguity.

\subsection{The expected probability of electoral victory}

Parties want to win the election. Observe that parties face uncertainty on the identity of the decisive issue as well as on the winning position on each issue. The probability of electoral victory equals the probability of winning with an issue times the probability that the issue will be decisive in the election. When parties compete on the same issue, this issue becomes decisive and their probability of victory coincides with their probability of holding the winning policy position on that issue. When parties campaign on different issues, the probability of victory is the expected probability of holding the winning policy position on the decisive issue.

Definition 5 Define the expected probability of victory $\Pi$ for a party proposing alternative $a_{i}$ on issue $i$, while the other party proposes alternative $a_{j}^{\prime}$ on issue $j$, as

$$
\Pi\left(a_{i}, a_{j}^{\prime}\right)=\left\{\begin{array}{ll}
\pi_{i}\left(a_{i}, a_{j}^{\prime}\right), & \text { if } j=i \\
s_{i j} \pi_{i}\left(a_{i}, q_{i}\right)+\left(1-s_{i j}\right)\left(1-\pi_{j}\left(a_{j}^{\prime}, q_{j}\right)\right), & \text { if } i \neq j
\end{array} .\right.
$$

Remember that this definition presumes that voters associate to the status quo the position of a party not proposing a policy alternative on an issue.

\subsection{Timing and equilibrium}

The political game consists of choosing policy issues and alternatives to compete on for the next election. It develops sequentially, following some order of play (See Fig. 1.). We give the incumbent government the first-mover advantage, capturing that governments can act while opposition parties can only make promises. Nevertheless, the order of play is not relevant for our results since it does not affect the set of issues chosen, but who chooses them, a feature we do not exploit. Hence, first we let the government party choose either to wait for the opposition to make a move $(w)$ or to take the initiative $(n w)$. Taking the initiative means that the government party chooses one issue 


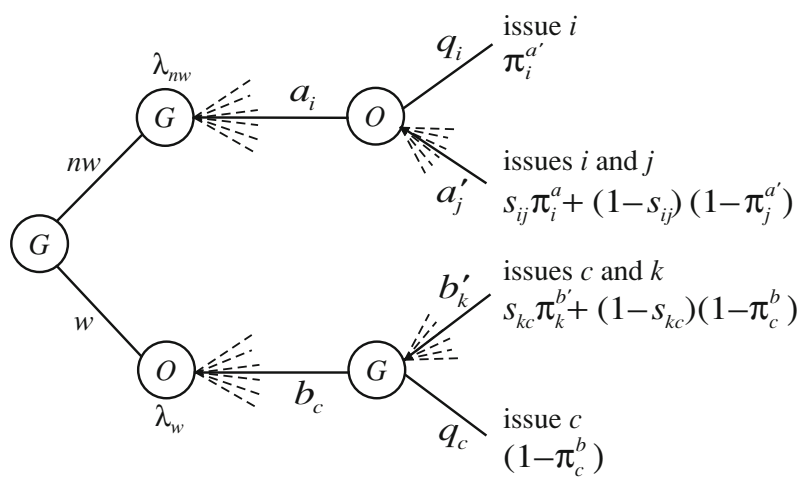

Fig. 1 Game tree. The final nodes represent the issues with political salience and the expected probability of victory for the incumbent government $G$

$i$ on which it proposes a policy alternative to the status-quo $a_{i} \in A_{i}, a_{i} \neq q_{i}$. Then the opposition party can fight the government party's proposal either by defending the status quo $q_{i}$, by defending the other alternative on the issue, or by devoting its efforts to raising another issue $j$ on which to propose a policy alternative $a_{j}^{\prime} \neq q_{j}, j \neq i{ }^{8}$ If, on the contrary, the government chooses waiting, the opposition can choose one issue $c$ on which to propose a policy alternative to the status-quo $b_{c} \in A_{c}, b_{c} \neq q_{c}$. Then the government party can either compete on the issue or raise a new issue $k$ (with $\left.b_{k}^{\prime} \neq q_{k}, k \neq c\right)$.

\section{The issue salience-policy agreement space}

Issues are characterized by the distribution of the preferences of the electorate $\left(\mathbf{F}_{i}^{x}, \mathbf{F}_{i}^{y}\right)$. Alternatively, from Definitions 2 and 3, we can describe issues by their degree of salience $\left(\sigma_{i}\right)$ and level of agreement $\left(\zeta_{i}\right)$. And for a given pre-campaign salience $\sigma_{i}$, we can write

$$
\zeta_{i}=\frac{2 F_{i}^{x}-\sigma_{i}}{\sigma_{i}}
$$

Figure 2 represents the issue salience and policy agreement space. We can identify three different areas. First, the rectangle ABEO captures all those issues which take relatively low salience among voters' pre-campaign concerns $\left(\sigma_{i}<1 / 2\right)$ thus implying relatively high support for the status-quo policies on the issues $\left(1-\mathbf{F}_{i}^{x}-\mathbf{F}_{i}^{y}>1 / 2\right)$. Given the high social consensus on the status-quo, it is unlikely that innovative policies are electorally successful (their probability of defeating the status-quo is less than one half) and parties will tend not to choose them in priority.

Second, the area BDE includes all those issues with relatively high salience $\left(\sigma_{i}>\right.$ $1 / 2$ ), but relatively low agreement on an alternative policy to the status-quo. This

\footnotetext{
8 Proposing the same alternative $a_{i}$ or the status-quo on a different issue $q_{j}, j \neq i$, are strictly dominated strategies yielding zero probability of victory.
} 


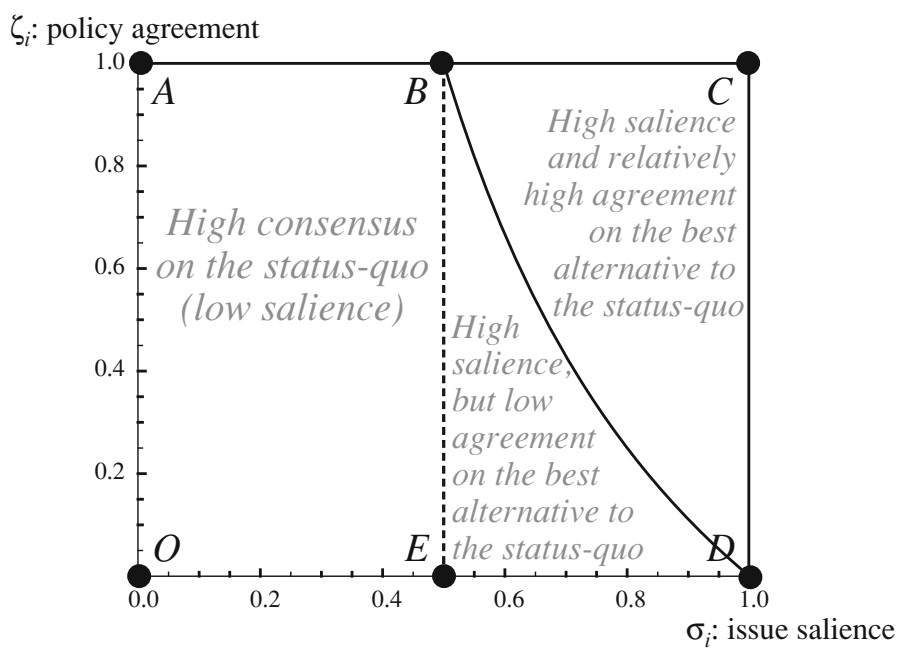

Fig. 2 The set of feasible pairs of issue salience and policy agreement

area is defined by the line $\zeta_{i}=\left(1-\sigma_{i}\right) / \sigma_{i}$ which represents those issues whose probability of defeating the status-quo is exactly $1 / 2$ (that is, $\mathbf{F}_{i}^{x}=1 / 2$ ). For those issues below this line $\zeta_{i}<\left(1-\sigma_{i}\right) / \sigma_{i}$, and any policy alternative has a probability of victory against the status-quo less than $1 / 2$.

Finally, the area BCD in the upper-right corner encompasses all those issues which take relatively high salience $\left(\sigma_{i}>1 / 2\right)$ and on which there is relatively broad agreement on the best policy alternative to the status-quo $\left(\zeta_{i}>\left(1-\sigma_{i}\right) / \sigma_{i}\right)$. This area corresponds to the set of likely successful issues.

Proposition 1 An issue $i$ exhibits $\pi_{i}^{x}>1 / 2$ if and only if $\sigma_{i}>1 / 2$ and $\zeta_{i}>$ $\left(1-\sigma_{i}\right) / \sigma_{i}$.

\section{Proof See Appendix.}

In the salience-agreement space of Fig. 2, we could draw a map of level curves for different probabilities of defeating the status-quo. ${ }^{9}$ Each curve includes all the combinations of issue saliencies and agreements on a policy alternative producing the same probability to win the election. In Fig. 3 we have represented several of those curves for the simple case where $\pi_{i}^{x}=\mathbf{F}_{i}^{x}$. The closer is the curve to the upper right corner, the higher the probability that campaigning on any of the issues located on the curve will defeat the status-quo. We will use this representation later in the paper to discuss examples of the party's choice of different issues in their electoral campaigns.

\footnotetext{
9 Formally, letting $l\left(\bar{\pi}^{x}\right)$ be the set of issues whose favored alternative defeats the status-quo with probability $\bar{\pi}^{x}$, we can write $l\left(\bar{\pi}^{x}\right)=\left\{\left(\sigma_{i}, \zeta_{i}\right) \in[0,1]^{2}: \zeta_{i}=\left(2 \varphi_{i}^{-1}\left(\bar{\pi}^{x}\right)-\sigma_{i}\right) \sigma_{i}\right\}$, where, recall, $\varphi_{i}\left(\mathbf{F}_{i}^{x}\right)$ is the probability that $x_{i}$ defeats $q_{i}$ when a fraction $\mathbf{F}_{i}^{x}$ of voters favor $x_{i}$.
} 


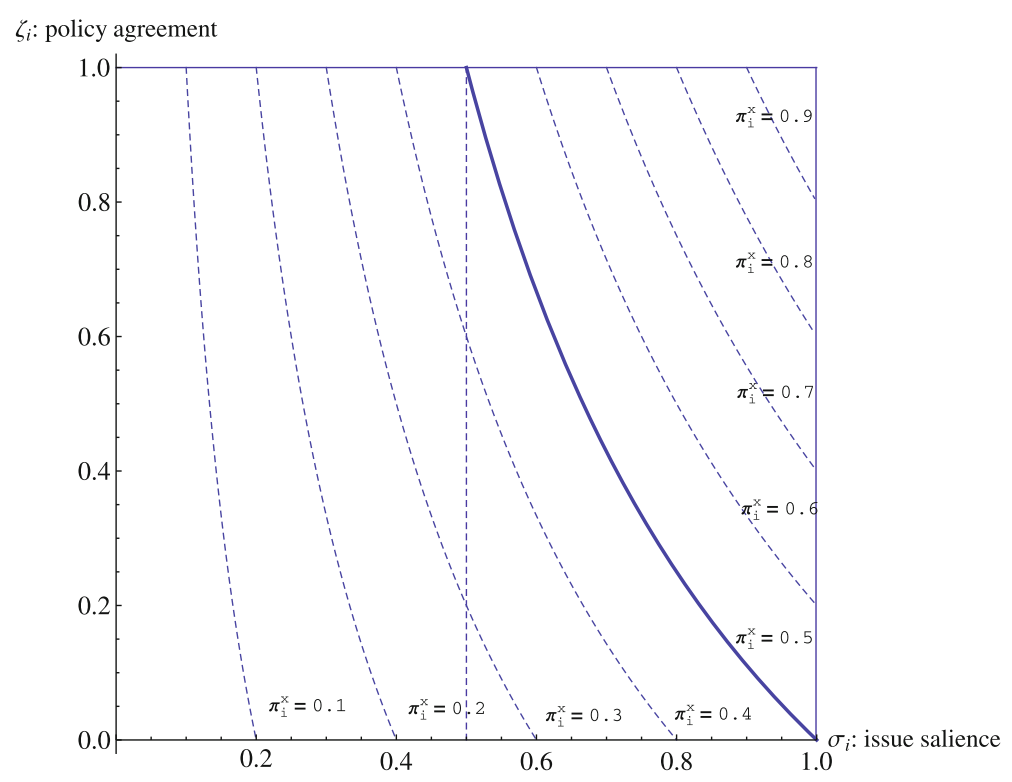

Fig. 3 Issue alternatives with iso-probability of defeating the status-quo

\section{Equilibrium results}

We focus the analysis on subgame perfect equilibria, the standard concept in sequential games with complete information. Such equilibria are characterized by:

1. the government choosing:

i) either taking the initiative or waiting,

ii) a policy alternative on one issue in case of taking the initiative,

iii) and a strategy in response to each possible policy alternative proposed by the opposition;

and by

2. an opposition choosing:

i) a strategy in response to each policy alternative proposed by the government in case the government takes the initiative, and

ii) a policy alternative on one issue to propose in case the incumbent government does wait.

The strategies must be optimal responses in each subgame. Being a finite, zerosum game, a subgame perfect equilibrium always exists and parties have the same probability of victory in all equilibria.

Following standard backward induction, we start by finding the optimal actions of the players at each final decision node and continue working back to the beginning of the game. 


\subsection{Subgames $\Gamma_{w}$ and $\Gamma_{n w}$}

Let $\Gamma_{w}$ and $\Gamma_{n w}$ be the two proper subgames following the incumbent's choice of taking the initiative or waiting (Their initial nodes are labeled as $\lambda_{n w}$ and $\lambda_{w}$ in Fig. 1.). These two subgames are symmetric, and hence it suffices to analyze only one of them. Denote the first mover of each subgame ( $G$ in $\Gamma_{n w}$ and $O$ in $\left.\Gamma_{w}\right)$ as player 1 , and the second mover as player 2 . The following proposition and its corollary characterize the best response correspondence for player 2 .

Proposition 2 Let $B R\left(x_{i}\right)$ be the set of best responses of player 2 to the proposal $x_{i}$ by player 1 . Then

1. $q_{i} \in B R\left(x_{i}\right)$ if and only if $1-\pi_{i}^{x} \geq \max _{k \neq i} \pi_{k}^{x}$.

2. $x_{j} \in B R\left(x_{i}\right)$ if and only if $1-\pi_{i}^{x} \leq \pi_{j}^{x}$, and $\left(\pi_{j}^{x}-\left(1-\pi_{i}^{x}\right)\right) s_{j i} \geq\left(\pi_{k}^{x}-(1-\right.$ $\left.\left.\pi_{i}^{x}\right)\right) s_{k i}$ for all $k \neq i, j$.

Proof See Appendix.

An implication of Proposition 2 is that the best response is independent of the precampaign salience $\sigma_{i}$, and thus of the degree of social discontent with the status-quo policy, whether the best response is defending the status quo or raising a new issue. This result will also hold in the full game, as discussed below.

Corollary 1 Consider the policy proposal $x_{i} \in A_{i}$.

1. If $i>1$, then

$$
B R\left(x_{i}\right)= \begin{cases}q_{i}, & \text { if } \pi_{i}^{x}<1-\pi_{1}^{x}, \\ \left\{q_{i}, x_{1}\right\}, & \text { if } \pi_{i}^{x}=1-\pi_{1}^{x}, \\ \arg \max _{x_{k} \neq x_{i}} \Pi\left(x_{i}, x_{k}\right), & \text { if } \pi_{i}^{x}>1-\pi_{1}^{x} .\end{cases}
$$

2. For $i=1$,

$$
B R\left(x_{1}\right)= \begin{cases}q_{1}, & \text { if } \pi_{2}^{x}<1-\pi_{1}^{x}, \\ \left\{q_{1}, x_{2}\right\}, & \text { if } \pi_{2}^{x}=1-\pi_{1}^{x}, \\ \arg \max _{x_{k} \neq x_{1}} \Pi\left(x_{1}, x_{k}\right), & \text { if } \pi_{2}^{x}>1-\pi_{1}^{x} .\end{cases}
$$

Proof See Appendix.

\subsection{The full game}

Consider the full game where the incumbent party may either take the initiative and propose a policy alternative on some issue (and hence play the subgame $\Gamma_{n w}$ ), or hold 
to the current situation and wait for the challenger to propose some alternative (and play subgame $\Gamma_{w}$ ).

As the following theorem shows, the equilibrium depends only on the two issues with the highest probabilities of victory. Whether parties compete on the same issue or raise different issues is independent of the pre-campaign issue salience, which reflects voters' concerns.

Theorem 1 Consider an agenda-setting political competition game.

1. If $\pi_{1}^{x} \leq 1 / 2$ or $\pi_{1}^{x} \geq 1-\pi_{1}^{x}>\pi_{2}^{x}$, then both parties compete on the same issue.

2. If $\pi_{1}^{x}>\pi_{2}^{x}>1-\pi_{1}^{x}$, then parties focus on different issues.

Proof See Appendix.

The intuition is not difficult to grasp. If there is not a good (likely successful) issue on which to propose a new policy alternative $\left(\pi_{1}^{x} \leq 1 / 2\right)$, then, at equilibrium, the government waits and, for each policy proposal of the challenger, it responds by defending the status quo on that issue. If there is a single best-alternative which is better than defending the status-quo and much better than any other alternative $\left(\pi_{1}^{x} \geq 1-\pi_{1}^{x}>\pi_{2}^{x}\right.$ ), then the government takes the initiative and proposes that policy alternative, while the opposition is forced to defend the status-quo on the issue. Finally, if there are promising policy alternatives on two issues $\left(\pi_{1}^{x}>\pi_{2}^{x}>1-\pi_{1}^{x}\right)$, the two parties raise different issues.

Equilibrium results can be presented in terms of issue salience and agreement on the policy alternative.

Theorem 2 Consider an agenda-setting electoral competition game in which parties choose issues to be raised during the electoral campaign; $\sigma_{i}$ is the degree of issue salience and $\zeta_{i}$ is the degree of agreement on a policy alternative to the status quo on issue $i$.

1. Let $\sigma_{1}<1 / 2$, then both parties focus on the same issue. The degree of issue salience is low (all the issues are within the rectangle ABEO in the Fig. 2). The government defends the status-quo on any issue challenged by the opposition, and the opposition chooses the best issue to challenge the status-quo. They may not choose the most salient issue.

2. Let $\sigma_{1}>1 / 2$, but $\zeta_{1}<\left(1-\sigma_{1}\right) \sigma_{1}$, then both parties focus on the same issue. Some issue takes high salience among voters, but there is no broad agreement on the best policy alternative to the status quo on the issue (all the issues are within the set ABDO in Fig. 2, with some in BDE), the opposition chooses the issue on which a policy alternative has the highest support, and the government defends the status-quo. They may not choose the most salient issue.

3. Let $\sigma_{1}>1 / 2$ and $\zeta_{1}>\left(1-\sigma_{1}\right) \sigma_{1}$, then the government chooses an issue with high salience and broad policy agreement. If there exists another issue with sufficient salience and agreement on the best policy alternative to the status-quo, the opposition chooses that issue and parties focus on different issues. The most salient issue may not be chosen. Otherwise the government proposes the best policy on the most salient issue and the opposition defends the status-quo on that issue.

Proof See Appendix. 
The following results show that the incumbent government can benefit from a higher probability of winning and always chooses an issue with relatively high salience and broad agreement (within the set BCD in Fig. 2), if there is any.

Corollary 2 Let $\rho=\max _{i} \min _{j \neq i} \Pi_{\mathrm{G}}\left(x_{i}, x_{j}\right)$. The incumbent government wins with probability $\max \{\rho, 1-\rho\}>1 / 2$.

Proof See Appendix.

Proposition 3 Suppose there exists at least one issue $i$ with $\sigma_{i}>1 / 2$ and $\zeta_{i}>$ $\left(1-\sigma_{i}\right) / \sigma_{i}$, then the issue chosen by the government at equilibrium exhibits both high salience and broad policy agreement, $\sigma_{G}>1 / 2$ and $\zeta_{G}>\left(1-\sigma_{G}\right) / \sigma_{G}$.

Proof See Appendix.

However, it is interesting to note that we cannot extend this latest result to the opposition, which may have to choose an issue with low salience or low level of agreement. To see this, consider the following case.

Example Consider an election in which three potential issues have the following distribution of support among the electorate:

$$
\left(\mathbf{F}_{1}^{x}, \mathbf{F}_{1}^{y}\right)=(0.7,0.15) ; \quad\left(\mathbf{F}_{2}^{x}, \mathbf{F}_{2}^{y}\right)=(0.51,0.14) ; \quad\left(\mathbf{F}_{3}^{x}, \mathbf{F}_{3}^{y}\right)=(0.49,0.41),
$$

which corresponds to the following salience and policy agreement values:

$$
\left(\sigma_{1}, \zeta_{1}\right)=(0.85,0.647) ; \quad\left(\sigma_{2}, \zeta_{2}\right)=(0.65,0.569) ; \quad\left(\sigma_{3}, \zeta_{3}\right)=(0.9,0.089)
$$

By Proposition 3 the government will not choose issue 2 because the degree of policy agreement is low: $\zeta_{3}<\left(1-\sigma_{3}\right) / \sigma_{3}=0.11$. In fact, the incumbent government will take the initiative and choose issue 1 , which is more salient and has broader agreement than issue 2. However, for the opposition to choose an issue, it is relevant to see that on issue 2 there is broader policy agreement than on issue 3 , but issue 2 is much less salient. In this case, the trade-off is favorable to issue 3, in spite of having low agreement. At equilibrium, the opposition does not choose issue 2, which has both high salience and broad agreement, $\sigma_{2}>1 / 2$ and $\zeta_{2}>\left(1-\sigma_{2}\right) / \sigma_{2}=0.538$, but chooses $x_{3}$ instead. ${ }^{10}$ Hence Proposition 3 does not apply to the opposition party.

Finally, observe that Proposition 3 also shows that the only situation in which we can guarantee that the most salient issue is brought up during the electoral campaign is when there is broad agreement on the best alternative in this issue and all other issues show very low salience.

\footnotetext{
$\overline{10}$ For all the examples we take $\pi_{i}^{x}=\mathbf{F}_{i}^{x}$ and $\pi_{i}^{y}=\mathbf{F}_{i}^{y}$, and compute equilibria using Mathematica. The program code can be obtained from the authors by request.
} 


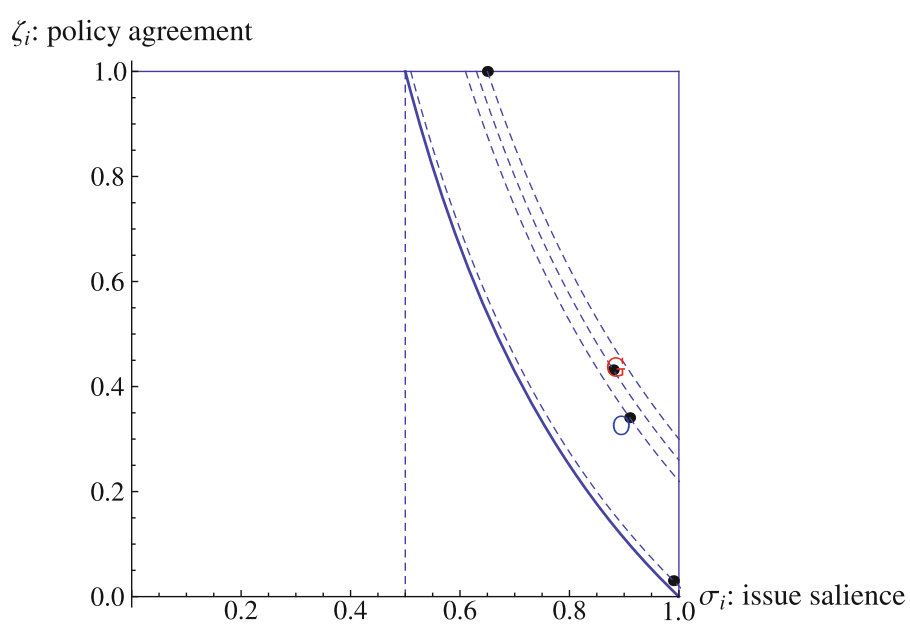

Fig. 4 Example 1: Neither the most salient nor the most consensual issues are chosen

\section{Examples}

We provide two numerical examples that illustrate how the trade off between salience and winning position shapes can induce parties competing in setting the electoral agenda to overlook the concerns of the electorate, as represented by issue salience, by choosing either to defend an unpopular status-quo on the issue or not talking about it at all.

5.1 Example 1: Neither the most salient issue nor the most consensual issues are chosen

Consider an election with four potential issues whose distribution of support among the electorate is represented by

$$
\begin{array}{ll}
\left(\mathbf{F}_{1}^{x}, \mathbf{F}_{1}^{y}\right)=(0.65,0.00) ; & \left(\mathbf{F}_{2}^{x}, \mathbf{F}_{2}^{y}\right)=(0.63,0.25) ; \\
\left(\mathbf{F}_{3}^{x}, \mathbf{F}_{3}^{y}\right)=(0.61,0.30) ; & \left(\mathbf{F}_{4}^{x}, \mathbf{F}_{4}^{y}\right)=(0.51,0.48),
\end{array}
$$

which corresponds to the following salience and policy agreement values:

$$
\begin{array}{ll}
\left(\sigma_{1}, \zeta_{1}\right)=(0.65,1.00) ; & \left(\sigma_{2}, \zeta_{2}\right)=(0.88,0.432) \\
\left(\sigma_{3}, \zeta_{3}\right)=(0.91,0.34) ; & \left(\sigma_{4}, \zeta_{4}\right)=(0.99,0.03)
\end{array}
$$

as represented in Fig. 4.

In equilibrium, government and opposition focus on different issues, 2 and 3 respectively. Specifically, the government takes the initiative and announces $x_{2}$ and the opposition responds by choosing $x_{3}$. Both parties overlook issue 4 , which is the most salient issue ( $99 \%$ of the electorate want to change the status-quo), and issue 1 , which is the 
$\zeta_{i}:$ policy agreement

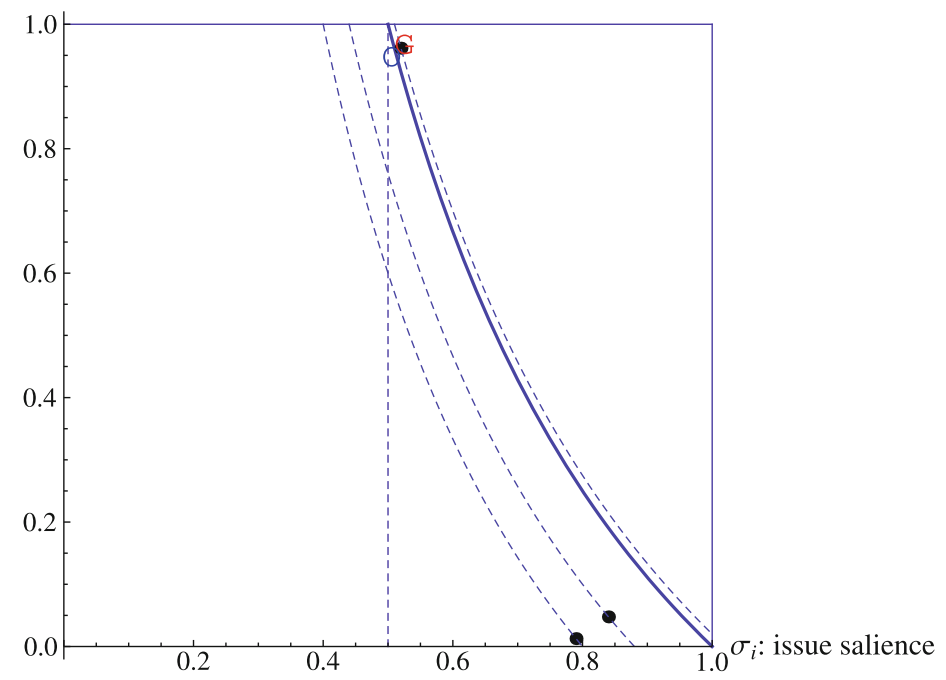

Fig. 5 Example 2: Parties may focus on the least salient issue

one with highest agreement (everybody in favor of changing the status-quo agrees on the alternative policy). Nevertheless, they focus on issues with either higher levels of agreement than issue 4 or more salience than issue 1 .

\subsection{Example 2: Parties may focus on the least salient issue}

Consider an election in which three potential issues have the following distribution of support among the electorate

$$
\left(\mathbf{F}_{1}^{x}, \mathbf{F}_{1}^{y}\right)=(0.51,0.01) ; \quad\left(\mathbf{F}_{2}^{x}, \mathbf{F}_{2}^{y}\right)=(0.44,0.40) ; \quad\left(\mathbf{F}_{3}^{x}, \mathbf{F}_{3}^{y}\right)=(0.40,0.39),
$$

which corresponds to the following salience and policy agreement values:

$$
\left(\sigma_{1}, \zeta_{1}\right)=(0.52,0.96) ; \quad\left(\sigma_{2}, \zeta_{2}\right)=(0.84,0.048) ; \quad\left(\sigma_{3}, \zeta_{3}\right)=(0.79,0.012)
$$

as represented in Fig. 5.

The government chooses issue 1, the only one in BCD (recall Proposition 3). The opposition does not choose issues 2 or 3 for lack of agreement on the best policy on those issues, but it rather challenges the government on the same issue 1 . The electoral campaign focuses on the least salient issue.

In this case, the opposition does not challenge the highly unsatisfactory status-quo policies on issues 2 and 3 (with around $80 \%$ of electorate in favor of changing the status-quo) as they lack voters' agreement on the best alternative. Hence, if salient issues lack enough voters' agreement on the best alternative, the government and the 
opposition may ignore voters' concern and focus their electoral campaign on less salient issues (even the least salient one).

These are just specific examples to show possible occurrences. To approach more general results, we can note that parties will never choose the issue with both the lowest salience and the highest controversy or lowest agreement on the appropriate policy alternative. But regarding highly salient issues, if there is not sufficiently broad agreement on a policy alternative, the opposition party may choose not to challenge a highly unsatisfactory status-quo policy and the incumbent government may survive in spite of its bad policy performance.

\section{Illustration}

Some features of the model could be illustrated with cases from the real world if the basic variables - pre-campaign issue salience in voters' concerns and agreement in favor of one of the policy alternatives on each issue - could be operationalized with data from survey polls and electoral campaigns. Just as an informal example to show the analytical potential of the model let us take the United States presidential election in $2004 .^{11}$

This case seems sufficiently close to our assumptions regarding a two party competition for a single office by plurality rule. Several survey polls asked voters to identify the most important issues in the 2004 U.S. presidential election. Observers broadly coincide in identifying 'moral values', 'the economy', 'terrorism', and 'the Iraq war', in this order, followed by others with minor impact such as 'health care', 'taxes', and 'education'. Broad agreement was obtained in favor of the alternatives promoted by the Republicans on 'terrorism', 'moral values' and 'taxes', in this order, and in favor of the alternatives promoted by the Democrats on 'the economy', 'health care', 'education', and 'the Iraq war', also in this order [see National Election Pool (2004), Stroud and Kenski (2007), as well as similar operazionalizations for previous elections by RePass (1971), McCombs and Zhu (1995), Burden and Sanberg (2003), and discussion by Wlezien (2005)].

Regarding the actual choice of issues during the electoral campaign by the two major candidates, Republican George W. Bush and Democrat John Kerry, there is also high coincidence in the academic literature. On the basis of people's responses to the 'most important issue' question, Weisberg (2005) conjectured that "people who supported Bush naturally would have chosen terrorism as their top concern. Kerry argued that the Iraq war was a diversion from the fight against Al Qaeda, so his supporters would likely have chosen Iraq as their first concern." (p. 784). While indeed Democratic activists and opinion-makers pressured in favor of Kerry campaigning mainly about 'Iraq' in response to Bush's emphasis on 'terrorism', polls show that most people agreed with the statement that the Iraq war was part of the war on terrorism (Norpoth and Sidman 2007 as observed by).

\footnotetext{
11 A complete and rigorous analysis of this event is beyond the scope of the paper as it would require, among other things, studying issue ownership, campaign resources, valence issues, etc.
} 
However, while Bush indeed chose 'terrorism' as the first issue, Kerry did not focus on 'Iraq', but on 'the economy'. "George W. Bush ran for re-election as a war-time president, emphasizing the importance of staying the course on the 'War on Terrorism'. At the same time, the economy had not fully recovered from the recession, and the job picture remained lackluster; his opponent, John Kerry, stressed the economy and other domestic issues such as health care" (Weisberg 2005, p. 777; see also Weisberg and Christenson 2007).

Other empirical analyses confirm the basic traits just remarked. According to Abramson et al. (2005), vote decisions were based largely upon retrospective evaluation of Bush as a successful president and as a leader who would be successful in combating terrorism, while moral values and social issues had low importance. In a close analysis, it is noted that as the threat of terrorism remained a substantial concern through election day and afforded Bush an overwhelming advantage, although the state of the economy and the war in Iraq were viewed negatively by most voters (Abramson et al. 2005). In another stance by Campbell (2005), it is remarked that the influence of the campaign was affected by major concerns that Kerry would not handle the war on terrorism as well as Bush, while there were more divided views about the economy and Iraq.

We can observe that none of the candidates chose to campaign in priority for the issue which could have higher pre-campaign salience among voters, 'moral values'. Numerous observers noted that, in spite of pundits' comments, 'moral values' ranked low in the issues list predicting actual voters' choices at the end of the electoral campaign (Langer and Cohen 2005, for instance). Republican candidate George W. Bush, instead of choosing this issue, on which he obtained relatively high support and advantage regarding the other candidate, chose the one in which his policy had the highest support, even if it was considered less important by the voters, 'terrorism'. Democratic candidate John Kerry did not choose in priority the issue 'Iraq', which, as mentioned, would have been a direct response to the initiative in favor of 'terrorism' taken by Bush, apparently for lack of agreement on the best alternative policy. He instead chose the issue in which he could obtain the highest agreement, 'economy/jobs'. Both candidates gave, thus, priority to those issues in which they could expect more popular agreement with their policy alternatives among the voters and higher advantage regarding the other candidate, rather than those which were more salient in voters' concerns.

\section{Conclusion}

We have presented an agenda-setting model of electoral competition in which parties choose to give salience and campaign on those issues on which they expect their policy proposals will obtain voters' broad support.

Parties have to trade off the pre-campaign salience of each issue in voters' concerns and the voters' support or agreement in favor of the policy alternatives on the issue. We have found that, although parties will not compete on irrelevant issues (those with both low salience among voters and divisive policy proposals), indeed the issues which are considered the most important ones by a majority of votes may not be given salience during the electoral campaign. 
As we noted at the beginning, this may be surprising, but not unreasonable after all. Even if there is extensive public concern on some issue, if there is not a single policy proposal on the issue which can attract broad agreement, focusing on that issue might produce high division and polarization among both parties and voters.

In the short term, mediocre policies broadly rejected by the electorate, as well as incumbent parties with no good performance in government, may survive for lack of a sufficiently convincing alternative. Since parties tend to choose to campaign on issues on the basis of relatively popular policies, in the long term broad policy consensus can be accumulated on an increasing number of issues. But since parties do not always choose to campaign on the issues with the highest pre-electoral salience, the political agenda may successively select, address and settle policy issues in an order which may not correspond to their importance in voters' concerns.

\section{Appendix: Proofs}

\section{A Proof of Proposition 1}

Because $\pi_{i}^{x}=\varphi\left(\mathbf{F}_{i}^{x}\right)$ with $\varphi^{\prime}>0$ and $\varphi(1 / 2)=1 / 2$, it suffices to show that $\mathbf{F}_{i}^{x}>1 / 2$ if and only if $\sigma_{i}>1 / 2$ and $\zeta_{i}>\left(1-\sigma_{i}\right) \sigma_{i}$.

1. Let $F_{i}^{x}>1 / 2$. Then $\sigma_{i}>1 / 2$ (Definition 2). Because $\zeta_{i}$ is increasing in $F_{i}^{x}$, then $\zeta_{i}>\left(1-\sigma_{i}\right) \sigma_{i}$, where we have substituted $F_{i}^{x}=1 / 2$ in (3).

2. Let $\sigma_{i}>1 / 2$. From (3), we can obtain $F_{i}^{x}=\sigma_{i}\left(1+\zeta_{i}\right) / 2$. Hence, $F_{i}^{x}>1 / 2$ if and only $\zeta_{i}>\left(1-\sigma_{i}\right) \sigma_{i}$. Therefore, if $\sigma_{i}>1 / 2$ and $\zeta_{i}>\left(1-\sigma_{i}\right) \sigma_{i}$, then $F_{i}^{x}>1 / 2$.

\section{B Proof of Proposition 2}

1. We know that $q_{i} \in B R\left(x_{i}\right)$ if an only if $\Pi_{2}\left(q_{i}, x_{i}\right) \geq \Pi_{2}\left(x_{k}, x_{i}\right)$ for all $k \neq i$. That is, if and only if $1-\pi_{i}^{x} \geq s_{k i} \pi_{k}^{x}+\left(1-s_{k i}\right)\left(1-\pi_{i}^{x}\right)$ for all $j \neq k$.

Since $s_{k i} \in(0,1)$, the inequality holds if and only if $1-\pi_{i}^{x} \geq \pi_{k}^{x}, \forall k \neq i$, which is equivalent to the condition in the statement: $1-\pi_{i}^{x} \geq \max _{k \neq i} \pi_{k}^{x}$.

2. Similarly, $x_{j} \in B R\left(x_{i}\right)$ if and only if it is better than choosing the status-quo in $i\left(\Pi_{2}\left(x_{j}, x_{i}\right) \geq \Pi_{2}\left(q_{i}, x_{i}\right)\right)$ and better than choosing a policy alternative in another issue $k \neq i, j\left(\Pi_{2}\left(x_{j}, x_{i}\right) \geq \Pi_{2}\left(x_{k}, x_{i}\right)\right)$. The first condition is equivalent to $s_{j i} \pi_{j}^{x}+\left(1-s_{j i}\right)\left(1-\pi_{i}^{x}\right) \geq 1-\pi_{i}^{x}$, that is, $\pi_{j}^{x} \geq 1-\pi_{i}^{x}$. The second condition implies that for all $k \neq i, j, s_{j i} \pi_{j}^{x}+\left(1-s_{j i}\right)\left(1-\pi_{i}^{x}\right) \geq s_{k i} \pi_{k}^{x}+\left(1-s_{k i}\right)\left(1-\pi_{i}^{x}\right)$. Simplifying, $\left(\pi_{j}^{x}-\left(1-\pi_{i}^{x}\right)\right) s_{j i} \geq\left(\pi_{k}^{x}-\left(1-\pi_{i}^{x}\right)\right) s_{k i}$.

\section{Proof of Corollary 1}

Recall that $\pi_{1}^{x}>\pi_{2}^{x}>\pi_{i}^{x}$ for all $i>2$. Observe that

$$
\Pi\left(x_{j}, x_{i}\right)=s_{j i} \pi_{j}^{x}+\left(1-s_{j i}\right)\left(1-\pi_{i}^{x}\right)=\left(1-\pi_{i}^{x}\right)+s_{j i}\left(\pi_{j}^{x}-\left(1-\pi_{i}^{x}\right)\right) .
$$


Hence, maximizing $\Pi\left(x_{j}, x_{i}\right)$ with respect to $x_{j}$ for a given $x_{i}$ is equivalent to maximizing $s_{j i}\left(\pi_{j}^{x}-\left(1-\pi_{i}^{x}\right)\right)$, namely, the expression in part 2 of Proposition 2. Therefore, the results follow directly from Proposition 2.

\section{Proof of Theorem 1}

We proceed case by case.

1. Let $\pi_{1}^{x} \leq 1 / 2$. Then $\pi_{i}^{x}<\pi_{1}^{x} \leq 1 / 2 \leq 1-\pi_{1}^{x} \forall i>1$. It follows from Corollary 1 that $B R\left(x_{k}\right)=q_{k}$ for all issue $k$, implying that both parties compete on the same issue.

2. Let $\pi_{1}^{x} \geq 1-\pi_{1}^{x}>\pi_{2}^{x}$. Then $1-\pi_{1}^{x}>\pi_{i}^{x}$ for all $i>1$. From Corollary 1 , $B R\left(x_{i}\right)=q_{i}$ for all $i$, and hence both parties compete on the same issue.

3. Let $\pi_{1}^{x}>\pi_{2}^{x}>1-\pi_{1}^{x}$. Let $\left(a_{1}^{*}, a_{2}^{*}\right)$ be the policy alternatives of an equilibrium outcome. We only need to show that $a_{2}^{*}=x_{i}$ for some $i$ and hence parties give political salience to different issues. Suppose that, on the contrary, $a_{2}^{*}=q_{k}$ for some $k$. Then $\left(a_{1}^{*}, a_{2}^{*}\right)=\left(x_{k}, q_{k}\right)$ and player 1 wins with probability $\Pi\left(x_{k}, q_{k}\right)=\pi_{k}^{x}$. From Corollary 1 , it must be that $\pi_{k}^{x} \leq 1-\pi_{1}^{x}$. By definition, $\Pi\left(x_{1}, B R\left(x_{1}\right)\right)=\min _{i>1}\left\{s_{1 i} \pi_{1}^{x}+\left(1-s_{1 i}\right)\left(1-\pi_{i}^{x}\right)\right\}>1-\pi_{1}^{x}$, since $\pi_{1}^{x}>1-\pi_{i}^{x} \geq 1-\pi_{1}^{x}$. But then $\Pi\left(x_{1}, B R\left(x_{1}\right)\right)>1-\pi_{1}^{x} \geq \pi_{k}^{x}$, and so $x_{1}$ is a better choice than $x_{k}$ for player 1 , a contradiction with $\left(x_{k}, q_{k}\right)$ being the equilibrium policies. Therefore, it cannot be that $a_{2}^{*}=q_{k}$ and parties must give political salience to different issues.

\section{E Proof of Theorem 2}

1. Let $\sigma_{1}<1 / 2$, then $\pi_{1}^{x}<1 / 2$ (Proposition 1 ). From Theorem 1 , both parties focus on the same issue. At the subgame $\Gamma_{s}(s=w, n w)$ player 2 always responds by defending the status-quo. Hence player 1 chooses issue 1 , the one with the highest probability of victory, and player 2 defends the status-quo $q_{i}$ against any alternative $x_{i}$. Player 1 wins with probability $\pi_{1}^{x}$. When deciding whether to take the initiative or wait, the government compares $\Pi_{G}\left(\Gamma_{w}\right)=1-\pi_{1}^{x} \geq \pi_{1}^{x}=\Pi_{G}\left(\Gamma_{n w}\right)$ and chooses to wait, where (abusing notation) $\Pi_{G}\left(\Gamma_{S}\right)$ represents the incumbent government's expected probability of victory associated to any Nash Equilibrium of the subgame $\Gamma_{s}$. Therefore, at the equilibrium path of the full game the opposition chooses $x_{1}$ while the incumbent government defends the status-quo in all issues. Consider the following example with issues $\left(F_{1}^{x}, F_{1}^{y}\right)=(0.3,0.1),\left(F_{2}^{x}, F_{2}^{y}\right)=$ $(0.25,0.2)$ and $F_{i}^{x}<F_{2}^{x}$ for all $i>2$. Observe that $1 / 2>\pi_{1}^{x}>\pi_{2}^{x}>\pi_{i}^{x}$ for all $i>2$ since $\pi_{j}^{x}<1 / 2$ if and only if $F_{j}^{x}<1 / 2$. Hence, since both parties focus on issue 1 at equilibrium and $\sigma_{2}=0.42>0.4=\sigma_{1}$, they do not choose the most salient issue.

2. Let $\sigma_{1}>1 / 2$ and $\zeta_{1}<\left(1-\sigma_{1}\right) / \sigma_{1}$. From Proposition $1, \pi_{1}^{x}<1 / 2$. Theorem 1 implies that both parties focus on the same issue. An argument similar to the one used in the previous case shows that the opposition chooses issue 1 and the government waits and defends the status-quo. Consider the following example. $\left(F_{1}^{x}, F_{1}^{y}\right)=(0.4,0.2),\left(F_{2}^{x}, F_{2}^{y}\right)=(0.35,0.3)$ and $F_{i}^{x}<F_{2}^{x}$ for all $i>2$. 
Observe that $\sigma_{2}=0.65>0.6=\sigma_{1}>1 / 2$ and $\zeta_{1}=0.33<0,66=\left(1-\sigma_{i}\right) /\left(\sigma_{i}\right)$. Hence, both parties choose issue 1 , while issue 2 shows higher salience (although lower level of policy agreement).

3. Let $\sigma_{1}>1 / 2$ and $\zeta_{1}>1 / 2$. From Proposition $1, \pi_{1}^{x}>1 / 2$. By Theorem 1 , if $\pi_{2}^{x}>1-\pi_{1}^{x}$ they focus on different issues, otherwise they choose the same issue. Let $k=\varphi^{-1}\left(1-\pi_{1}^{x}\right)$, that is the electoral support that an alternative $x$ would need to defeat the status-quo with probability $1-\pi_{1}^{x}$. Then, $\pi_{2}^{x}>1-\pi_{1}^{x}$ if and only if $\mathbf{F}_{2}^{x}>k$. The inequality $\mathbf{F}_{2}^{x}>k$ holds if and only if $\sigma_{2}>k$ and $\sigma_{2}\left(1+\zeta_{2}\right)>k$. Therefore, if there exists another issue with enough salience and policy agreement (namely $\sigma_{2}>k$ and $\zeta_{2}>\left(2 k-\sigma_{2}\right) / \sigma_{2}$ where $k=\varphi^{-1}\left(1-\pi_{1}^{x}\right)$ ) parties focus on different issues, otherwise they both compete on the same issue. As the examples in Sects. 5.1 and 5.2 show, they may not choose the most salient, nor focus on issue 1 and 2.

\section{F Proof of Corollary 2}

We know that $\rho=\max _{i} \min _{j} \Pi_{1}\left(x_{i}, x_{j}\right)$ and $(1-\rho)$ are the values of the games $\Gamma_{n w}$ and $\Gamma_{w}$, respectively, and that the incumbent government can choose the subgame to play by waiting or taking the initiative. Therefore, the government will choose the subgame with the highest value and hence its probability of winning will be $\max \{\rho, 1-\rho\} \geq 1 / 2$.

\section{G Proof of Proposition 3}

1. By Proposition 1, we only need to show that if the incumbent government chooses an issue $G$, then $\pi_{G}^{x}>1 / 2$. Assume that there exists an issue $i$ such that $\sigma_{i}>1 / 2$ and $\zeta_{i}>1 / 2$. Then, $\pi_{i}^{x}>1 / 2$ and hence $\pi_{1}^{x}>1 / 2$, as $\pi_{1}^{x} \geq \pi_{i}^{x}$ for all $i$.

2. Suppose that $\pi_{G}^{x}<1 / 2$.

(a) Then $\pi_{2}^{x}>1-\pi_{1}^{x}$, otherwise the government could choose issue 1 at equilibrium and obtain $\Pi_{G}^{*}=\pi_{1}^{x}>1 / 2$.

(b) Because $\pi_{2}^{x}>1-\pi_{1}^{x}$ we know by Theorem 1 that parties choose different issues and, by Corollary $2, \Pi_{G}^{*}>1 / 2>\Pi_{O}^{*}$.

(c) Moreover, it must be that $\pi_{O}^{x}<1 / 2$. Otherwise $\Pi_{G}^{*}=s_{G O} \pi_{G}^{x}+(1-$ $\left.s_{G O}\right)\left(1-\pi_{O}^{x}\right)<1 / 2$, a contradiction with the previous step.

(d) If the government does not wait $\left(\Gamma_{n w}\right)$, it must be that $\Pi_{O}^{*} \geq s_{i G} \pi_{i}^{x}+(1-$ $\left.s_{i G}\right)\left(1-\pi_{G}^{x}\right)$ for all $i \neq G$. Since $\Pi_{O}^{*}<1 / 2$ and $1-\pi_{G}^{x} \geq 1 / 2$, it follows that $\pi_{i}^{x} \leq 1 / 2$ for all $i \neq G$. But this is a contradiction with the initial assumption that $\pi_{1}^{x}>1 / 2$.

(e) If the government waited at equilibrium, the opposition could always choose issue 1 and guarantee a probability of victory of at least $\underline{\Pi}=\min _{i \neq 1} s_{i 1} \pi_{1}^{x}+$ $\left(1-s_{i 1}\right)\left(1-\pi_{i}^{x}\right) \leq \Pi_{O}^{*}$. Because $\Pi_{O}^{*}<1 / 2$ and $\pi_{1}^{x}>1 / 2$, it follows that $\pi_{i}^{x} \geq 1 / 2$ for all $i$. But this is a contradiction with the government choosing an issue with $\pi_{G}^{x}<1 / 2$.

Therefore we have proved that at equilibrium $\pi_{G}^{x}>1 / 2$. It follows from Proposition 1 that $\sigma_{G}>1 / 2$ and that $\zeta_{G}>1 / 2$. 
Open Access This article is distributed under the terms of the Creative Commons Attribution License which permits any use, distribution and reproduction in any medium, provided the original author(s) and source are credited.

\section{References}

Abramson PR, Aldrich JH, Rohde DW (2005) The 2004 presidential election: the emergence of a permanent majority? Polit Sci Q 120(1):33-57

Abramson PR, Aldrich JH, Rohde DW, Rickershauser J, Rohde DW (2007) Fear in the voting booth: the 2004 presidential election. Polit Behav 29(2):197-220

Amorós P, Puy SM (2007) Dialogue or issue divergence in the political campaign? CORE Discussion paper 2007/84

Amorós P, Puy SM (2010) Indicators of electoral victory. Public Choice 144:239-251

Baumgartner FR, Jones BD (2009) Agendas and instability in American politics. The University of Chicago Press, Chicago

Budge I (1993) Issues, dimensions, and agenda change in postwar democracies: long-term trends in party election programs and newspaper reports in twenty-three democracies. In: Agenda formation. Oxford University Press, Oxford, pp 41-80

Budge I, Klingemann H-D, Volkens A, Bara J, Tanenbaum E (2001) Mapping policy preferences: estimates for parties, electors, and governments 1945-1998. Oxford University Press, Oxford

Burden BC, Sanberg JNR (2003) Budget rhetoric in presidential campaigns from 1952 to 2000. Polit Behav 25:97-118

Campbell JE (2005) Why Bush won the presidential election of 2004: incumbency, ideology, terrorism, and turnout. Polit Sci Q 120:219-241

Colomer JM, Puglisi R (2005) cleavages, issues and parties: a critical overview of the literature. Eur Polit Sci 4(4):502-520

Klingemann H-D, Volkens A, Bara J, Budge I, McDonald MD (2006) Mapping policy preferences II: Estimates for parties, electors and governments in Central and Eastern Europe, European Union and OECD 1990-2003. Oxford University Press, New York

Krasa S, Polborn M (2010) The binary policy model. J Econ Theory 145(2):661-688

Langer G, Cohen J (2005) Voters and values in the 2004 election. Public Opin Q 69(5):744-759

McCombs M, Zhu J-H (1995) Capacity, Diversity, and volatility of the public agenda: trends from 1954 to 1994. Public Opin Q 59(4):495-525

National Election Pool (2004) Exit poll for ABC-AP-CBS-CNN-Fox News-NBC News. Edison Media Research \& Mitofsky International, provided by Voter News Service (VNS). http://edition.cnn.com/ ELECTION/2004/pages/results/states/US/P/00/epolls.0.html

Norpoth H, Sidman A (2007) Mission accomplished: the wartime election of 2004. Polit Behav 29(2):175195

Petrocik JR (1996) Issue ownership in presidential elections, with a 1980 case study. Am J Polit Sci 40(3):825-850

Petrocik JR, Benoit WL, Hansen GJ (2003) Issue ownership and presidential campaigning, 1952-2000. Polit Sci Q 118(4):599-626

RePass DE (1971) Issue salience and party choice. Am Polit Sci Rev 65(2):389-400

Riker WH (1993) Agenda formation. University of Michigan Press, Michigan

Roemer JE (2001) Political competition: theory and applications. Harvard University Press, Cambridge, MA

Stokes DE (1963) Spatial models of party competition. Am Polit Sci Rev 57(2):368-377

Stroud NJ, Kenski K (2007) From agenda setting to refusal setting: survey nonresponse as a function of media coverage across the 2004 election cycle. Public Opin Q 71(4):539-559

Weisberg H, Christenson D (2007) Changing horses in wartime? The 2004 presidential election. Polit Behav 29(2):279-304

Weisberg HF (2005) The US presidential and congressional elections, November 2004. Elect Stud 24(4):777-784

Wittman D (1983) Candidate motivation: a synthesis of alternative theories. Am Polit Sci Rev 77:142-157

Wlezien C (2005) On the salience of political issues: the problem with 'most important problem'. Elect Stud 24(4):555-579 